\title{
A incrível proeza dos alunos-pesquisadores na construção de conhecimentos geográficos e na leitura do lugar - Experiências do projeto \#SomosMario
}

\author{
La increíble hazaña de los estudiantes-investigadores en la construcción \\ de conocimiento geográficoy la lectura del lugar - Experiencias del \\ proyecto\#SomosMario
}

\author{
Juliana Garcia Nunes (julianasociologia@ hotmail.com) \\ UFRGS - Universida deFederal do Rio Grande doSul
}

\begin{abstract}
Resumo: $\mathrm{O}$ artigo "A incrível proeza dos alunos-pesquisadores na construção de conhecimentos geográficos e o espantoso poder da Geografia na leitura do lugar Experiências do projeto\#SomosMario" foi um projeto de intervenção, construído por educandos (as) do $6^{\circ}$ ano do Ensino Fundamental de uma escola municipal do Bairro Mário Quintana, comunidade da periferia de Porto Alegre/RS. A pesquisa teve como objetivo abordar, através de conceitos geográficos (espaço, lugar, território), a história, a cultura, a identidade e a espacialidade do Bairro Mário Quintana, em que os educandos, a partir de suas dúvidas, curiosidades, ansiedades, problematizações e interesses, produziram conhecimentos geográficos a respeito da localidade, enxergando o bairro como um Lugar, alterando regimes de visibilidade, de um espaço violento, perigoso, estigmatizado como "território do crime" pelos constantes homicídios e "toques de recolher" para uma visibilidade que fortaleceu e valorizou a identidade do lugar e o sentimento de pertencimento, construindo uma cidadania espacial nos adolescentes participantes do projeto. A aplicação da metodologia da pesquisa-ação, entendida como uma intervenção pontual em problema coletivo a ser solucionado, proporcionou aos educandos voz sobre as vivências na localidade, e compreendê-las, papel do en sino de Geografia: "entender o lugar para compreender o mundo".
\end{abstract}

Palavras-chave: Lugar; Ensino de Geografia; Identidade; Pesquisa-ação.

Resumen: El artículo "La increíble hazaña de los estudiantes-investigadores en la construcción del conocimiento geográfico y el asombroso poder de la Geografía en la lectura del lugar - Experiencias del proyecto \#SomosMario" fue un proyecto de intervención, construido por estudiantes de $6^{\circ}$ de Primaria. de una escuela municipal en Bairro Mário Quintana, una comunidad en las afueras de Porto Alegre / RS. La investigación tuvo como objetivo abordar, a través de conceptos geográficos (espacio, lugar, territorio), la historia, cultura, identidad y espacialidad del Barrio Mário Quintana, en el que los estudiantes, a partir de sus dudas, curiosidades, ansiedades, problematizaciones e intereses, produjeron conocimiento geográfico sobre la localidad, viendo el barrio como un lugar, cambiando regímenes de visibilidad, desde un espacio

Recebido em: 30 /04/ 2020

Aceito em: 19/11/2020 
violento, peligroso, estigmatizado como "territorio del crimen" por constantes homicidios y "toques de queda" por visibilidad que fortaleció y valoró la identidad del lugar y el sentimiento de pertenencia, construyendo una ciudadanía espacial en los adolescentes participantes del proyecto. La aplicación de la metodología de investigación-acción, entendida como una intervención puntual en un problema colectivo a resolver, brindó a los estudiantes una voz sobre las experiencias de la localidad para comprenderlas, el rol de la enseñanza de la Geografía: "comprender el lugar para entender el mundo".

Palabras clave: Lugar; Enseñanza de la Geografia; Identidad; Investigación para la Acción.

\section{INTRODUÇÃO}

\#SomosMario é um projeto de intervenção, iniciado em 2016, construíd o por educandos do $6^{\circ}$ ano do Ensino Fundamental de uma escola municipal do Bairro Mário Quintana, comunidade da periferia de Porto Alegre/RS. A investigação teve como objetivo abordar, através de conceitos geográficos (lugar, paisagem, território, pertencimento), a história, a cultura, a identidade e a espacialidade dos estudantes, a partir das suas dúvidas, curiosidades, ansiedades, problematizações e interesses, produziram conhecimentos geográficos a respeito da localidade, enxergan do o espaço como um Lugar.

Durante as aulas de Geografia, os (as) educandos (as) traziam saberes e imaginários sobre o bairro como um espaço que imperava a violência e o perigo de "levar um tiro", estigmatizado como "território do crime”. Sentimentos de repúdio e topofobia ${ }^{1}$ eram muito comuns durante as aulas. Porém, através de estudos geográf icos realizados por eles e elas, ocorreu uma alteração no olhar, uma nova visibilidade que fortaleceu e valorizou a identidade do lugar e o sentimento de pertencimento. A aplicação da metodologia da pesquisa-ação, entendida como uma intervenção pontual num problema coletivo a ser solucionado, proporcionou aos educandos voz sobre as vivências na localidade, compreendê-las, papel do ensino de Geografia: "entender o lugar para compreender e intervir no mundo".

\footnotetext{
${ }^{1}$ Topofobia, segundo Guimarães (2002), é o desprezo, aversão a alguns lugares na experiência ambiental dos indivíduos, guardados na memória, no mosaico paisagístico vivido. GUIMARÃES, Solange. Reflexões a respeito da paisagem vivida, topofilia e topofobia à luz dos estudos so bre a experiência, percepção e interpretação ambiental. Florianó polis: GEOSUL, v.17, n. 38, 2002.
}

Recebido em: 30 /04/ 2020

Aceito em: 19/11/2020 
A ideia do projeto \# SomosMario começou das angústias da professora, durante as aulas de Geografia, já que encontrava muitas dificuldades em desenvolver os conteúdos relacionados ao Lugar dos estudantes. Em uma das aulas, a professora começou o "conteúdo", com o estudo do conceito de Lugar, conforme indicava o livro didático e o plano de ensino, sem saber previamente os acontecimentos do bairro. Lugar é aquele espaço que conhecemos muito bem a história, a paisagem, as mudanças e as permanências. Há sentimento de pertencimento, afeto e carinho ao local. Após a exposição, os educandos iniciaram a sua parte, questionando esse "conceito de Lugar”, pois a "vila" a qual habitavam não era um "Lugar", era uma "vila de bandidos", onde viviam em "guerra”, com a presença constante do tráfico de entorpecentes, homicídios e assaltos. Um aluno conclui com a seguinte frase: "Essa Geografia nãopresta para nada...”.

Esses acontecimentos narrados não são incomuns nas aulas de Geografia. Os adolescentes são problematizadores da realidade e apontam de forma imediata às fraturas de uma didática falha, sem conexão com o contexto da comunidade a qual a escola está inserida. Parte dos (as) professores (as) enxergariam o tal aluno como "indisciplinado". Outros (as) tentariam compreender o porquê do olhar depreciativo sobre o bairro e, talvez, mostrar que a Geografia presta para compreender a relação do homem com o ambiente-sociedade-cotidiano, ou melhor, como nós sobrevivemos espacialidade. Sendo assim, Castrogiovanni (2014) expõe os obstáculos que a escola apresenta:

\begin{abstract}
Existe a inda pouca aproximação da escola com a vida, com o cotidiano dos a lunos. A escola não se manifesta atraente frente ao mundo contemporâneo, pois não dá conta de explicar e tex tualizar as novas leituras de vida. A vida fora da escola é cheia de mistérios, emoções, de sejos e fantasias, como tendem a ser as ciências. A escola parece serhomogênea, tran sparente e sem brilho no que se refere a tais características. É urgenteteorizar a vida, para que o aluno possa compreendê-la e representa-la melhor e, portanto, viver em busca de seus interesses. (CASTROGIOVANNI, 2014,p. 13)
\end{abstract}

Dessas indagações nasce o projeto “\#SomosMario”. Após reflexões, estudos sobre a história socioespacial da localidade, assim como, uma mudança pedagógica nas práticas de ensino em Geografia, foi possível compreender que, no fundo, o principal problema que os (as) educandos (as) traziam para a sala de aula (a violência) era fruto da falta de conhecimento que os adolescentes possuíam sobre o território que viviam.

Recebido em: 30 /04/ 2020

Aceito em: 19/11/2020 
Era necessário desconstruir o imaginário pejorativo do Bairro Mário Quintana e enxergar o espaço como um Lugar, de identidade e pertencimento, através do conhecimento dos seus territórios, produção de saberes, de Itinerários de Descoberta, trilhas, mapas, maquetes, organização de entrevistas com moradores antigos e novos, desbravar a paisagem, a vegetação, o clima, arroios, estrutura geológica, a atuação de movimentos sociais populares, compreensão de processos e transformações da região, enfim, produzir uma "cartografia do espaço", para romper com a autoestima baixa dos (as) alunos (as) e buscar uma cidadania socioespacial que, no entender de Nogueira \& Carneiro (2013):

Contribua para a compreensão da dimensão es pacial dos fenômenos da rea lida de-mundo, sob os a spectos dos meios físico-natural e humano-social, conexos e interdependentes; pois é a partir desse entendimento que os a lunos terão condições de formar a titudes e desenvolver ações criterios a e consequentes na realidade do seu dia a dia (NOGUEIRA \& CAR NEIRO, 2013,p. 161).

A hashtag "\#SomosMario", símbolo que nas redes sociais significa a categorização de algum fato, acontecimento ou até uma campanha, é sempre publicada em forma de hiperlink. Nesta intervenção, tem o valor da constituição de uma corrente, que convida os (as) educandos (as) e a comunidade Mário Quintana a conhecerem o território e valorizá-lo.

\section{A LEITURA DO LUGAR}

É impossível um estudo geográfico sem contextualizar o espaço cujo projeto foi desenvolvido e os sujeitos participantes dessa intervenção: educand os do $6^{\circ}$ ano do Ensino Fundamental moradores do Bairro Mário Quintana. Freire (1997) já apontava que o ponto de partida é sempre a leitura de mundo do (a) educando (a).

Respeitar a leitura de mundo do educando significa tomá-la como ponto de partida para a compreensão do papel da curiosidade, de mo do ge ra l, e da humana, de modo especial, como um dos impulsos fundantes da pro dução do conhecimento. (FREIRE, 1997, p. 123)

O Bairro Mário Quintana está localizado na parte nordeste da cidade de Porto Alegre. Possui uma população de aproximadamente sessenta mil habitantes, de maioria 
afrodescendente e pertencente às classes populares. Aliás, a maior população negra da cidade encontra-se nesta localidade.

A região, no passado, distante da área central, era povoada por poucas chácaras (o antigo nome era Capão da Fumaça). A partir da década de 1980, tornou -se um receptáculo de populações removidas, desterritorizadas dos seus lugares, reassentadas no espaço sem as mínimas condições de moradia adequada ${ }^{2}$.

Atualmente, compõem a localidade quarenta e três vilas, das quais a penas seis são regularizadas. As demais são caracterizadas por ocupações irregulares, em áreas de risco, sem saneamento básico entre outros recursos.

Conhecida na mídia como um dos espaços mais violentos de Porto Alegre, apresenta um dos mais baixos IDH - Índice de Desenvolvimento Humano da cidade. Toques de recolher por conflitos de gangues rivais em disputa por ponto de ven da de entorpecentes, homicídios, invasões e reintegrações de posse fazem parte da rotina da localidade, assim como, da escola.

Quanto aos sujeitos-alunos (as) participantes do projeto, foram categorizados em três grupos, segundo o perfil socioantropológico ${ }^{3}$, levantamento feito pela professora, o que explicou o porquê de tanto repúdio ao bairro: 1) Os (as) alunos (as) "Raiz": nasceram na localidade. Enxergam o espaço como um Lugar. Possuem identidade e pertencimento; 2) Os (as) alunos (as) moradores recentes, os outsiders ${ }^{4}$, chegaram no bairro há dois, três anos ou há poucos meses, representando a maioria da turma. As suas referências espaciais estão nos antigos bairros ou municípios de moradia (Viamão, Quintão, Guaíba, Alvorada, Balneário Pinhal, Alegrete, Gravataí, Passo

\footnotetext{
${ }^{2}$ Ma is informações em: PREFEITURA MUNICIPALDE PORTO ALEGRE. Chá ca ra da Fumaça. Projeto Memória Popular: SMC, 1999.

${ }^{3}$ O Perfil Socioantropológico foi uma prática, no início da implementação dos Ciclo s de Formação na Rede de Ensino de Porto Alegre, em 1999. O principa lobjetivo da construção doperfil era p ro duzir u m levantamento de temas, umainvestiga ção da comunidad e escolar, pa ra contextualizar na escola o "conhecimento emergente da realidade atual expressa pelo contexto sócio-histórico culturaldos educandos". Mais informações em Ciclos de Formação: proposta político pedagógico da Escola Cid a dã. Ca derno Pedagógico número 9. Prefeitura Municipal de Porto Alegre. Secretaria Municipal de Educação, 1998.

${ }^{4}$ Estra nho, intruso. A palavra foi u sa da no estudo etnográfico de ELIAS, Nobert; SCOTSON, John L. Os Estabelecimentos e os outsiders: sociologia das relações de poder a partir de uma pequena comunid a de. Rio de Ja neiro: Zahar, 2004.
}

Recebido em: 30 /04/ 2020

Aceito em: 19/11/2020 
Edição Especial: XVI Encontro sobre Investigação na Escola - EIE

Fundo, General Câmara e etc.). Enxergam a violência e os problemas do bairro. O outro lugar é sempre mais seguro. Não demonstram tanto repúdio em estudar a história da comunidade; 3) Alunos (as) moradores de ocupações: esse grupo de alunos são moradores de loteamentos irregulares e ocupações. Apreensivos, nunca sabem se vão retornar para a escola na próxima aula. A polícia (Brigada Militar) é uma presença constante pelo cumprimento da reintegração de posse do terreno ocupado. Não possuem territoriedade, identidade, pertencimento, não querem saber a história do bairro, já que, a princípio, vão ficar temporariamente no bairro.

A par de tais dados, ficou nítida a necessidade de uma intervenção pedagógica, em busca de uma prática docente comprometida com a realidade dos adolescentes. Produzir conhecimentos positivados da localidade pelos próprios educandos foi inevitável para "salvar" as aulas de Geografia. A metodologia aplicada foi a pesquisa-ação, pois queríamos resolver um problema para o qual já possuíamos a resposta: por que não gostamos do bairro? Porque não conhecemos a sua história. Foi necessária a construção de uma leitura do lugar a partir do olhar deles e delas.

\subsection{A PESQUISA-AÇÃO}

A pesquisa-ação não é "qualquer metodologia". Ela é especial, singular e particular. Os participantes (professores e sujeitos-alunos) do processo de conhecimento têm que estar envolvidos e sensibilizados na investigação, participando de todas as etapas ou ciclos do projeto, desde a construção do problema, a coleta de dados, divulgação, organização das atividades e avaliação, com o intuito de resolver a situação, que além de ser proposto e investigado por eles e elas, também os toca, afeta e engaja na busca de mudanças e transformação. Thiollent (2008) afirma que a pesquisa-ação é:

[...] um tipo de pesquisa social com base empírica que é concebida e realizada em estreita associação com uma ação ou resolução de um problema coletivo e no qual os pesquisadores e os participantes representativos da situação ou do problema estão en volvidos de modo cooperativo ou participativo. (THIOLLENT, 2008, p. 16)

Podemos dividir a pesquisa-ação em três fases: a fase exploratória, a fase de elaboração e execução do Plano de Ação e a fase de Divulgação dos Resultados.

Recebido em: $30 / 04 / 2020$

Aceito em: 19/11/2020 
A primeira etapa da pesquisa-ação é a fase exploratória, o ponto de partida da investigação. É identificado o problema e o tema da pesquisa. Debates e dinâmicas de grupo foram aplicados, construção de mapas mentais, "explosão de ideias", desacomodando preceitos e imaginários. Essa fase teve a duração de quatro semanas. Foi aplicada a estratégia pedagógica "O que eu conheço como a palma da minha mão". Os (as) educandos (as) tinham que escolher cinco espaços do bairro que eles e elas conheciam muito bem, frequentavam diariamente, possuíam afeto e fazem parte das suas histórias de vida. Usaram as suas próprias mãos como molde e, nos dedos, escreveram os lugares. Para jovens que não possuíam nada "positivado" para falar sobre o território, foi um avanço.

Após a fase exploratória, iniciou-se a elaboração e a execução do Plano de Ação. Os encontros, nesta etapa, são chamados de seminários. É o espaço no qual o diálogo é exercitado, bem como decisões sobre a investigação. Os en contros são re gistrados em atas, ocorreu a elaboração das diretrizes (hipóteses de pesquisa), votações, relatórios de síntese, preparo dos (as) alunos-pesquisadores. É permitida a visita de palestrantes, professores, moradores da comunidade. Nesta fase, há coleta de dados (por exemplo, entrevistas, saídas de campo, observações participantes, construção de maquetes e mapas da localidade) e a produção de diários de campo são socializadas. Os (as) educandos (as) exercem a função de pesquisadores.

Os (as) alunos-pesquisadores foram divididos em três grupos, dando in ício à investigação: o Geoespacial, o Geoantropológico e o Geoambiental.

\subsubsection{O GEOESPACIAL}

O grupo Geoespacial ficou responsável pela construção do mapa do Bairro Mário Quintana, apontando os principais espaços identitários da comunidade. Os (as) alunos-pesquisadores desconheciam o território, as outras localidades que fazem parte da região. Começaram a valorizar e descobrir outras espacialidades, como o Parque Chico Mendes (um dos maiores parques de Porto Alegre), a casa de Vó Chica (Maria Francisca Gomes Garcia, mulher negra, que foi benzedeira, contadora de histórias e 
Edição Especial: XVI Encontro sobre Investigação na Escola - EIE

ISSN: 2595-4520 Vol. 4, n. 2. 2021

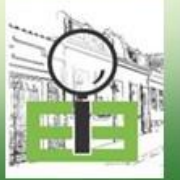

liderança comunitária, falecida em 1983), a escola como um espaço de identidade e o Morro Santana, patrimônio ambiental da cidade, foram pontuados de forma positivada pelos (as) alunos-pesquisadores. Começaram a enxergar comunidade como um Lugar.

\subsubsection{O GEOAMBIENTAL}

O grupo Geoambiental produziu um levantamento ambiental sobre o território. Foi construída uma mapoteca ecológica com o clima, a vegetação, biótipo natural, a estrutura geológica, morros e arroios ( figuras 1,2) e que compõem a paisagem da comunidade. Os (as) alunos-pesquisadores utilizaram os estudos a partir dos conhecimentos do Atlas Ambiental de Porto Alegre (1999) e visitas ao Institu to de Geociências da Universidade Federal do Rio Grande do Sul - UFRGS, na Faculdade de Geologia com o professor Rualdo Menegat, um dos autores do atlas. Saíd as de campo foram realizadas para identificação do solo e do "valão" (figura 3), vertente do arroio Passo das Pedras que, casualmente, termina seu curso na esquina da escola. Os problemas ambientais ganharam destaque, como o descarte irregular de resíduos. O conhecimento construído pelo grupo e as descobertas foram de extrema importância para a valorização do patrimônio ambiental do bairro.

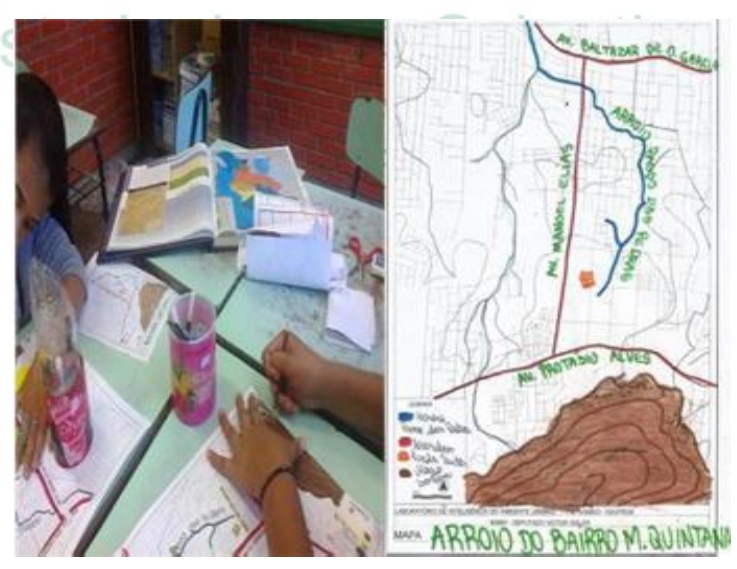

Figuras 1 e 2 - Construção da mapoteca ecológica. Fonte: A Autora (2017).

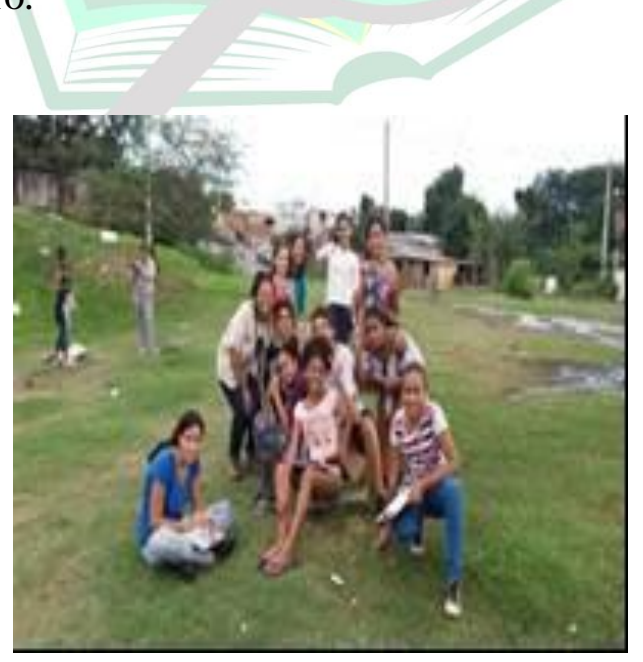

Figura 3: Saída de Campo ao Arroio Passo das Pedras. Fonte: A Autora (2017).

\subsubsection{O GEOANTROPOLÓGICO}

Recebido em: 30 /04/ 2020

Aceito em: $19 / 11 / 2020$ 
O grupo Geoantropológico ficou responsável pelas entrevistas, empregando a metodologia da História Oral ${ }^{5}$. Moradores do entorno da escola, professores, funcionários, pais e mães, ex-alunos da escola deram os seus depoimentos, sobre a história do bairro, bem como suas experiências e vivências locais. Foi construída uma Linha do Tempo com os principais fatos da localidade. O grupo descobriu que muitas lutas e conquistas foram realizadas por Movimentos Sociais Populares em busca de melhores das condições de vida e direitos (educação, saúde, segurança, habitação). O entorno da escola é carregado de elementos que devem estar presentes nas aulas de Geografia.

\subsubsection{DIVULGAÇÃO DOS RESULTADOS}

A última fase da metodologia da pesquisa-ação é a Divulgação dos Resultados. Trata-se da comunicação do estudo realizado no Plano de Ação, assim, tornando pública a experiência vivenciada pelos (as) alunos-pesquisadores. As apresentações iniciaram no segundo semestre de 2018, com grande participação da comunidade (figura 4). Em 2019, participaram do Salão Jovem da UFRGS (figura 5), divulgando os estudos. Isso denota a proeza, a coragem e façanha que o ensino da Geografia e de estudantes devidamente estimulados e instigados podem proporcionar ao conhecimento, tornando-o significativo. O grupo não apresenta sentimentos de topofobia ou repúdio ao Bairro Mário Quintana. Trazem para as aulas as dificuldades da localidade, medos, mas querem, de alguma forma, intervir na realidade e resolver os problemas. Isso é cidadania socioespacial, como Nogueira \& Carneiro (2013) apontaram, papel da Geografia.
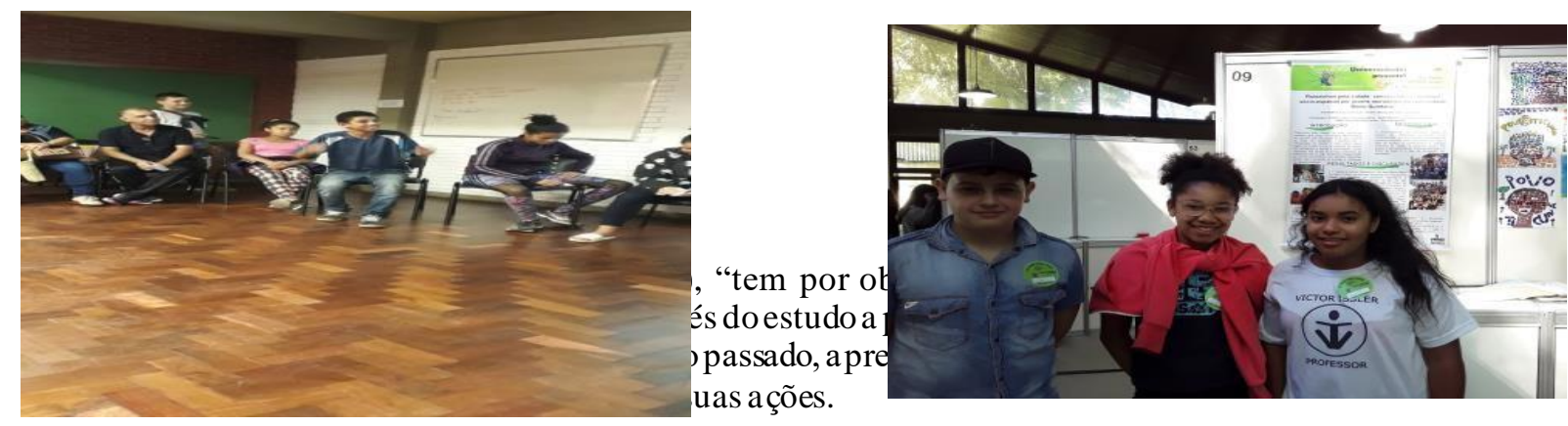

Recebido em: 30 /04/ 2020

Aceito em: 19/11/2020 
Figura 4 - Apresentação dos estudos do projeto\#SomosMario. Fonte: A Autora (2019).
Figura 5 - Sa lã o Jovem FRGS. Fonte: A Autora (2019).

\section{ANÁLISE E DISCUSSÃO DO RELATO}

A primeira aprendizagem do projeto \#SomosMario foi transformar a escola e os saberes dos (as) sujeitos-alunos em conhecimento. Segundo Nunes (2018, p. 76), a partir do perfil socioantropológico foi possível conhecer os educandos, nos seus aspectos afetivos, emocionais, geográficos, o lugar próximo, ou seja, a realidade na qual estão inseridos. A proximidade com o lugar do educando oportuniza mais autonomia para a construção de novos conhecimentos e aprendizagens. No entender de Costella \& Shaffer (2012):

O lugarpróximoé oferecidocomoleitura inicial, pois o entendimen to do contexto do aluno, de como ele se vê, como se reconhece neste lugar, como reconhece os outros, é o primeiro passo para que compreenda outros elementos identitários, em diferentes escalas geográficas. Ta is a spectos dão identidadea um lugare podem ser tratados seja por sua presença, no lu gar de vida dos a lunos, ou por sua a usência. (COSTELLA \& SHAFFER, 2012 , p.65).

No entender de Nunes (2018), é imprescindível aflorar em sala de aula essas falas, experiências dos educandos, abrindo o diálogo, quer dizer, escuta atenta, uma sensibilidade apurada por parte do professor, que se torna um professor-reflexivopesquisador ${ }^{6}$ da sua própria prática docente. Fala-se aqui de provocar um estranhamento do lugar, chamar a atenção para outros "saberes" sobre a comunidade levando, calmamente, a uma reflexão crítica, por mais duras, conflituosas, violentas e cruéis que sejam, pois, é a partir desses fatos que criamos as nossas "munições geográficas" para um trabalho que realmente transforme a realidade, uma intervenção no mundo, uma superação das condições que os colocam em desvantagem, os limita, os exclui, tornando-os cidadãos conscientes, como mostraram os resultados do projeto.

\footnotetext{
${ }^{6}$ Para Nunes (2018,p. 93) o professor (a)-pesquisador (a)é aquele profissional que entende a pesquisa como eixo da formação docente. Além disso, são profissionais que possuem uma prática refle xiva sobre o trabalho, estudam as suas próprias experiências, procuram compreender como o educando a prende, para melhor ensinare, de toda a sorte, intervir para uma socie dade melhor para os adolescentes.
}

Recebido em: 30 /04/ 2020

Aceito em: 19/11/2020 
Outro ponto que o projeto \#SomosMario fez refletir foi sobre o ensino de Geografia que vem sendo praticado nas escolas: estática, "tradicional”, mostrando as “coisas pelas coisas", os “dados pelos dados", a "Geografia pelo número".

A escola muitas vezes parece tratar a Geografia Escolar como senso comum. \#SomosMario é uma intervenção que mostra ser possível produzir conhecimentos na escola, e não somente reproduzi-los com base no livro didático. É evidente que a rotina escolar desmotiva os seus educadores, em meio a planejamentos burocráticos, uma infinidade de horas a cumprir, lutas e mobilizações por melhores condições salariais e de trabalho, a desvalorização da profissão, a agitação dos alunos, percebe-se a emergência constante da utilização da linha de pensamento tradicional. Alguns colegas desistem de ensinar, somente escrevendo textos para os alunos copiarem e responderem às perguntas para serem entregues no final da aula e "valendo nota". Deixamos de acreditar que há uma epistemologia sobre nosso ofício, uma pedagogia particular.

A Geografia tem que se prestar à desconstrução de naturalizações presentes nas falas dos (as) alunos (as), como, por exemplo, o Bairro Mário Quintana é "lugar de bandido", "estamos vivendo uma guerra", precisa evidenciar e compreender outros saberes que foram construídos por eles e elas. É possível não reproduzir uma geografia estática, uma “Geografia do silêncio”. Nas palavras de Kaercher (2010), a Geografia:

[...] fica parecida com a vegetação, com o clima, etc. Está lá. Ponto . Lo go, não há muito o que pensar, muito menos, modificar. Somos seres im ersos na rea lidade sem entendê-la. Parece que os a lunos são conservas num vidro. Dentro da sala um mundohermético, reduzidoà visão do professor que, no geral, é a visão do livro. Lá fora a realidade muito mais complexa e a meaçadora. (KAERCHER, 2010,p.67)

Por fim, ainda convém lembrar que \#SomosMario alterou o regime de visibilidade dos (as) sujeitos-alunos. O Regime de Visibilidade, para Gomes (2013), auxilia-nos a compreender o olhar como um fenômeno geográfico. $\mathrm{O}$ autor chama esse “olhar” de visibilidade. O fenômeno da visibilidade é defendido como um exercício de interpretação geográfica, de leitura privilegiada do espaço, isto é, uma investigação do olhar, das imagens, da posição que cada sujeito ou objeto ocupa em determinado lu gar, questionando preceitos como: “De onde vemos?”, “Como vemos?”, “O que se vê?”, 
“De onde ver?”, “Como compreender?”. Essas são excelentes perguntas para questionar os (as) sujeitos-alunos no estudo do território.

Imagens das coisas não estão jamais separadas dos lugares on de elas são exibidas. Por isso, há, sem dúvida, uma geografia que participa diretamente da produção de significações que nos veiculamas im agens. É todo esse imenso campo de estudos que cabe a os geógrafos que trabalham, dire ta ou indiretamente, com imagens desbravar e investigar. (GOMES, 2013, p. 31)

O fenômeno da visibilidadeé defendido por Gomes (2003) como um fato que apresenta uma incontornável geograficidade, todavia depende da posição do lu gar e de um sistema de referência espacial. A intervenção alterou a visiblidade dos (as) educandos (as). O olhar deles e delas estava voltado para a violência do bairro, permeados por sentimentos de topofobia e repúdio à localidade. Com os estudos construídos por eles e elas, a visibilidade foi focada em aspectos positivados da re gião, como o patrimônio ambiental, a história de vida dos moradores que lutaram por melhores condições de vida e a descoberta de outras espacialidades. Em con sequên cia disso, a prática docente torna-se significativa.

\section{CONSIDERAÇÕES FINAIS}

O objetivo do relato foi mostrar um pouco da experiência do projeto \#SomosMario, evidenciando que vale a pena fazer uma Geografia comprometida com a realidade dos (as) educandos (as). Intervenções geográficas podem alterar regimes de visibilidade. \#SomosMario foi uma forma de viabilizar a consciência espacial, ou seja, pensar a espacialidade na formação de cidadãos e cidadãs atuantes e conhecedores da comunidade que vivem e constroem as suas existências.

Tal intervenção é um desafio e uma ousadia, que somente professorespesquisadores da sua própria docência, angustiados com os rumos que a Geografia Escolar vem tomando, têm coragem de executar e ver sua prática pedagó gica fazendo alguma diferença para os (as) educandos (as), bem como, para comunidade onde a escola está inserida.

Apesar dos (as) alunos (as) agitados e desatentos, baixa remuneração do magistério e da rotina escolar exaustiva, outras formas de ensinar, a partir da Geografia

Recebido em: 30 /04/ 2020

Aceito em: 19/11/2020 
Edição Especial: XVI Encontro sobre Investigação na Escola - EIE

ISSN: 2595-4520 Vol. 4, n. 2. 2021

que vem deles e delas, é de extrema importância produções espaciais contextualizad as, compreendendo o que não está posto, o porquê das coisas acontecerem no mundo, dando voz aos sujeitos-alunos e à professora, num processo de interação e troca surgem novas estratégias para melhor ensinar, torna o ensino atraente e gratificante para os educadores comprometidos com a transformação da realidade de seus educandos.

\section{REFERÊNCIAS}

ALBERTI, Verena. Manual de História Oral. Rio de Janeiro: FGV, 2004.

CASTROGIOVANNI, Antônio Carlos. Apreensão e compreensão do espaço geográfico. In: CASTROGIOVANNI, A; CALLAI, H; KAERCHER, N. (Org.). Ensino da Geografia: práticas e textualizações no cotidiano. Porto Alegre: Mediação, 2014.

COSTELLA, Roselane Zordan \& SCHAFFER, N. A Geografia em projetos curriculares: ler o lugar e compreender o mundo. Erechim: Edelbra, 2012.

FREIRE, Paulo. Pedagogia da Autonomia. Rio de Janeiro: Paz e Terra, 1997. GOMES, Paulo Cesar da Costa. O lugar do Olhar. Rio de Janeiro: Bertand Brasil, 2013.

KAERCHER, Nestor André. Se a Geografia escolar é um pastel de vento o gato come a Geografia Crítica. Porto Alegre: Evangraf, 2014.

NOGUEIRA, V.; CARNEIRO, S. Educação Geográfica e Formação da Consciência Espacial- Cidadã. Curitiba: Editora UFPR, 2013.

MENEGAT, Rualdo (Org.). Atlas Ambiental de Porto Alegre. Porto Alegre: Editora da UFRGS/PMPA, 1999.

NUNES, Juliana G. \#somosmario: identidade, território e cultura: o que o ensino de Geografia tem a ver com isso?". Dissertação de Mestrado. Instituto de Geociências/ POSGEA/UFRGS, 2018.

T, Michel. Metodologia da Pesquisa-Ação. São Paulo: Cortez, 2008.

Recebido em: 30 /04/ 2020

Aceito em: 19/11/2020 